Functional primary education for sustainable quality

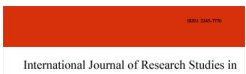
assurance in human capital development in Nigeria

\author{
Ayeni, Adeolu Joshua \\ Ondo State Quality Education Assurance Agency, Akure, Nigeria (ayeniadeolu@yahoo.com)
}

Adepoju, Taiwo Lanre

Faculty of Education, Obafemi Awolowo University, Ile-Ife, Nigeria (adepojutaiwo2004@yahoo.com)

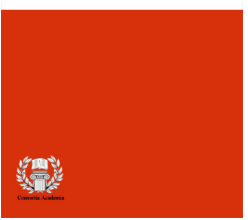

ISSN: $2243-7770$ Online ISSN: 2243-7789

Received: 18 May 2012

Revised: 13 June 2012

Accepted: 18 June 2012

OPEN ACCESS

\title{
Abstract
}

This paper examines the goals, issues and role of primary education in determining human capital formation, growth and functionality. It also highlights the vital role of teachers in developing pupils' learning capacities and trends in academic achievement and standards; and contributes to the understanding of policies in order to foster stakeholders' commitment to human capital development and ensure relevance to socio-economic advancement of the society.

Keywords: primary education; human capital; sustainable quality assurance; stakeholders' partnership; self-reliance 


\section{Functional primary education for sustainable quality assurance in human capital development in Nigeria}

\section{Introduction}

Sustainable quality assurance in human capital is the conscious process of ensuring optimum resource investment in human capacity training beginning from childhood education with consistent development in cognitive and non-cognitive skills which enables the individuals to become well informed, transformed, self-confident and productive, and contribute meaningfully to socio-economic advancement of the society.

Education is regarded as instrument par excellence and the means of achieving human capital and national develpment. This underscores the value being placed on quality and standards which encompasses quality learning resource inputs, instructional process, teachers' capacities development, effective management, monitoring and evaluation, and quality learning outcome in primary schools. The success of the educational system is reflected in the quality of human capital produced by the training institutions.

The Nigeria's National Policy on Education defines primary education as education given in an institution of learning for children aged normally 6 to 11 years plus for a duration of six years. The Primary Education is a sensitive period of human capital formation since the rest of the education system is built upon it; primary education is the bedrock of human capital development because the formation of skills in a certain period depends on the nature of learning and skills acquired from earlier periods and current investments. This implies that events and quality of training during primary education lay the foundation for all other education system and can have significant long term positive impact on adult outcomes. Yet, children can be permanently damaged at this stage if their mental, physical and character developments are not taken very seriously by teachers and parents.

Effective Primary Education can facilitate the development of cognitive skills such as intelligence, memory power and reasoning as well as non-cognitive skills such as self-regulation, value orientation and persistence social integration. The formation of skills is a cumulative, synergetic process which is affected by the environment, genetic endowments, and both formal and informal investments in education. Since "skills foster skills", skill formation in childhood will have lasting effects for the development of intelligence and self regulation as well as for learners' achievement scores, socio-economic success and human capital (Cunha \& Heckman, 2007; Heckhausen \& Heckhausen, 2006). The inequality of human capital is not only influenced by the heterogeneity of skills. The quality of education provided by the institutions will transform skills into human capital and wages in the labor markets which determines the socio-economic status as well.

Gregg and Machin (2000) examined the relationship between child development and labor market outcomes. Using sequential modeling and UK data, they found that behavioral problems at age 7 are associated with poorer educational outcomes at age 16, which in turn is associated with poor labor market outcomes at ages 23 and 33 . Furthermore, the children of parents who grew up in the socially disadvantaged situation during their own childhood have lower early age cognitive abilities, suggesting an important cross-generational link in human capital development. The behavioural problems associated with negative human capital are related with criminal, antisocial and violent activities. Individuals who experienced conduct disorder problems are more likely to leave school early, have poorer employment prospects and lower earnings.

On the other hand, positive human capital is generally developed through schooling and manifests in the assessment scores and educational attainment in terms of knowledge and skills acquired from curriculum instruction. Consequently, human capital is often measured with a three point scale (below average, average, better than average). Beginning from apprenticeship, diploma, certificate; technical or teachers' college; 
university first degree; and university postgraduate degree.

\section{Childhood Education Policy and Quality Expectations}

Provision of access to functional quality primary education is a fundamental human right of all citizens as provided by the 1948 United Nations Human Rights Act, and the Universal Basic Education (UBE) Act 2004 of the Federal Republic of Nigeria which stipulates free and compulsory nine years of formal schooling for all children of primary and junior secondary school age in Nigeria (UBE Act, May 2004). This Act also seeks to reinforce the national primary education goals and set targets for attaining universal primary education within the global Education for All (EFA) and Millennium Development Goals (MDG) context by year 2015. It is believed that education improves lives and strengthens human capacity; therefore it is imperative that learning begins in the early years of life. Primary education is critical in a child's development as it lays the foundation for success in school and beyond. And with $90 \%$ of the child's brain being developed by this period, quality early learning opportunities are important for all children regardless of demographic and socio-economic background.

The National Policy on Education (Federal Republic of Nigeria, 2004, Section 4(8), indicates that government's policy thrust and goals of primary education are to: 1) Inculcate permanent literacy, numeracy, and the ability to communicate effectively; 2) Lay a solid basis for scientific and reflective thinking; 3) Give citizenship education as a basis for effective participation in, and contribution to, the life of the society; 4) Mould the character and develop sound attitude and morals in the child; 5) Develop in the child, the ability to adapt to the child's changing environment; 6) Give the child opportunities for developing manipulative skills that will enable the child function effectively in the society within the limits of the child's capacity; and 7) Provide the child with basic tools for further educational advancement including preparation for trades and crafts of the locality.

Perhaps, to underscores the growing importance of this segment to the Nigerian Government, it provided $2 \%$ consolidated federal revenue fund for UBE and supported by local and international donor grants to adequately take care of childhood education and development programs to achieve both the national UBE and global EFA goals by 2015 .

In Nigeria, the target set for primary education is yet to be met since more than 10 million Nigerian children of school aged are not registered in schools. The $2 \%$ intervention fund dedicated to the Universal Basic Education (UBE) in Nigeria is grossly inadequate while the annual budgetary allocation varies from as high as $20-26 \%$ in a few states and less than $3.0 \%$ of the total education budget in others (Federal Ministry of Education, 2007). Consequently, there is low commitment to addressing the challenges of infrastructure, educational materials/equipment, capacity training for teachers, sensitization and advocacy, running grants, and monitoring and supervision of the primary schools. These problems are a bit more demanding and the opportunities are short of the effective implementation. There is also low commitment of stakeholders to primary education policy and programs while most of the primary schools are substandard and greater percentage of learners performed below the expectations of the society.

\section{Teacher's Role in Human Capital Development}

The quality of human capital is the overall effects of the educational system, which are expressed in terms of desirable changes in knowledge, skills, attitudes and values of individuals as a result of their experiences in the cognitive, affective and psychomotor domains of learning over a period of study (Simkins, 1981; Tsang, 1988). The training and assessment of learners by teachers play a pivotal role in determining the quality of learners' achievement and standards. The attainment of this goal is undoubtedly determined by effective curriculum management by the teacher while inadequate learning resource inputs constitutes a major challenge that inhibits the teacher's task in human capital development. The teacher's role among others include: instructional 
management, curriculum delivery, motivation of learners, assessment of learning outcomes and instructional feedback to the learners and other stakeholders to ensure consistent improvement in the teaching-learning process and the achievement of high-quality human capital development. This ultimately depends on the avowed commitment of teachers to make judicious and adequate use of both human and material resources to ensure quality assurance in the teaching-learning process.

Human capital development quality process requires that the teacher provides the transformation process which involves the teacher-learners interaction, appropriate methodologies, instructional materials and continuous assessment that focuses on child participation in curricula and co-curricular activities in which the learners derive their own ideas, values, skills and interpretations to what they are exposed while ensuring that the classroom instruction meets the set standards for children's empowerment. The teaching approach that a teacher adopts is an important factor that may affect learning achievement and facilitates high standards of learners' outcomes. The success or failure of learners rests on the quality of instruction and not lack of learners' abilities to learn (Levine, 1985; Mills, 1991).

In order to ensure quality human capital-oriented teaching and learning processes, the teachers are expected to have in-depth knowledge of the pedagogy in their subject areas to be able to understand the effective ways of organizing and presenting subject matter (objective statements, providing the right methods, learning experiences and learning resources), and evaluating teaching and learning activities in consonance with the set of objectives. This process enables the individuals to develop cognitive, affective and psychomotor powers for the discovery of their inner lying potential abilities for higher education, technical and vocational training, while in the long run, the students come out as outputs in form of educated persons (intended outputs) ready to enter the labor market for self-reliant and community development. Effective teaching-learning process is no doubt the fulcrum for human capital development in primary schools.

The pedagogic style practiced by teachers will need to be child-centered to address classroom activities that put the best interest of children at the centre of teaching-learning process. Banjo (1987), posited that, adequate training of teachers in the latest methodology, to a large extent, determines how the learner learns during instructional activities. This viewpoint was further stressed by Maduekwe (2007) in a study on the strategies for teaching English lessons in Lagos, that in spite of the fact that most of the teachers have teaching qualifications, many of them do not have adequate knowledge of some grammatical concepts and they ended up imparting the wrong knowledge to their students. This situation is a serious gap in the teaching-learning process and also constitutes threat to the attainment of sustainable quality assurance in human capital development in schools. It is therefore imperative of the teachers and school administrators to ensure effective teaching and thorough supervision of instructional activities so that learning outcome can meet the set standards in the development of human capital.

\section{Research Outcomes on Learning Achievement and Standards}

Research conducted by Candice Bennett and Associates (2009) on 507 American adults ages 18 and above in United State of America indicates that all the participants agreed that reading to kids fewer than 5 is the best method to develop early childhood literacy skills. What they don't know is a majority of low-income families do not have books for children in their homes. The study also reveals that: 1) Most Americans recognize the important interrelationship between books in the home and early childhood literacy skills; 2) $80 \%$ say storybook reading with an adult is a very effective way to help children under 5 develop early childhood literacy skills; and 3) $86 \%$ agree that access to books is the best way to help improve literacy skills of low-income kids.

The research further indicates that children exposed to quality early learning environments are more likely to perform well academically, be more socially and emotionally well-adjusted, abstain from delinquent behavior and graduate from high school. However, not all Arizona and Florida children have access to quality early learning opportunities due to the affordability and accessibility of quality settings as well as the need for higher 
Functional primary education for sustainable quality assurance in human capital development in Nigeria

skilled teachers and practitioners. As studies show, there is a direct correlation between teacher and professional education levels and the quality of childhood education programs. Yet, the majority of youngest children are in environments where their teachers are neither certified in childhood education nor have a college degree. In fact, most often, teachers and practitioners require additional education and skill development in order to create higher quality early learning experiences. There are also significant inconsistencies across existing programs and lack of alignment between childhood education and educator expectations.

It is also recognized that cultivating desirable learning attitude and language acquisition during the earliest years provides an important foundation for life-long learning; however, many early childhood education teachers do not understand the fundamental importance of creating a print and language rich environment. With growing expectations for academic mastery at younger ages, especially with the increased focus on Science, Technology, Engineering and Mathematics (STEM) learning across the education continuum, quality early learning becomes even more critical in setting the stage for long-term learners' success. Better understanding of the goals and objectives of early childhood education aids the successful transformation and transition of learners and fosters more sustained gains from the investments made in quality early childhood education programs.

In Nigeria, the level of learning achievement of pupils is relatively low in primary schools. According to the Federal Ministry of Education (2003) annual report, the assessment of the competency level of primary four pupils conducted in 1996 revealed the national mean scores for Numeracy (32\%), Literacy (25.2\%) and Life-skills (36.86\%), while the follow-up national assessment of learning achievement of primary five pupils in 2001 showed low levels of achievement in English (40.30\%) and Mathematics (34.02\%). The Federal Ministry of Education (2007) reported on the assessment of the level of learning achievement of pupils conducted in 2006 in the core subject areas of English Language (Literacy), Mathematics (Numeracy) and general knowledge: health and personal hygiene; primary science and agriculture (Life Skills); the purpose is to determine the effectiveness of policy measures on improving quality and efficiency of primary education delivery and the extent to which the EFA goal on quality assurance is being met at the primary level of education system.

The Monitoring of Learning Achievement results revealed that on the average at the national level, the performance of the pupils in Literacy, Numeracy and Life Skills was below $50 \%$ in both primary four and primary six, depicting poor performance. The national mean percentage scores recorded for primary four pupils were Numeracy (33.74), Literacy (35.05) and Life-skills (43.81) while the national mean percentage scores for primary six were Numeracy (35.73), Literacy (41.53) and Life-skills (25.42). Monitoring of learning achievement for basic education was carried out last in 2006 while attempts by the Federal Ministry of Education to coordinate follow-ups assessments have been constrained by reason of inadequate funding. However, with the renewed impetus in the operation of the Federal Inspectorate Services, it is hoped that the Federal Ministry of Education will ensure regular administration of the instrument as a monitoring tool for tracking systems' performance.

The abysmal performance of pupils in the monitoring of learning achievement tests depicts a low level of human capital development at the primary school level which is the bedrock of sustainable human capital and national development. As a result, there is a general public outcry about the standard of primary education and growing concern among the secondary school teachers that majority of the children transisting and entering their classrooms are not well prepared for learning success. There are factors such as inadequate teachers' capacity development, shortage of learning resources, poor staff motivation, funding, weak institutional supervision and management that are affecting the quality of curriculum delivery and thus the attendant result of non-attainment of quality learning outcome and set standards in primary schools.

The poor academic standard of pupils had been partly attributed to several challenges, some of which have been identified by Okebukola (1996) as lack of adequate infrastructure and large classes, inadequate incentive for teachers, delay in the implementation of promotion for teachers, late payment of teachers' salaries, and lateness to school, truancy, inadequate parental care and lack of textbooks. Okebukola (2011) further stressed 
that over 60 per cent of the teachers at the basic education level (primary and secondary) have abysmally low content knowledge, while over 90 per cent of public primary and secondary schools in Nigeria are sub-standard when measured against international standards in terms of quality of infrastructure, fittings, landscape and general school environment when compared with the conditions in equivalent schools in Europe, North America, Asia, South Africa and Egypt; thus the attendant result of non-attainment of quality education in secondary schools. This situation calls for concerted efforts from the teachers, head teachers, government and other stakeholders in education to device ways of tackling the problem of poor performance and low level of learning achievement of pupils in primary schools.

In a bid to reverse the downturn in the quality of primary education provision, learning achievement and standards, the Federal Ministry of Education in Nigeria made a paradigm shift from school inspection to Education Quality Assurance, which is an evolving education policy reform initiative that involves holistic monitoring and evaluation process and practice, aimed at improving the quality of school management, learning environment, curriculum delivery and pupils' learning achievement through the involvement of meaningful, close, strong and goal-oriented partnership between the school authority and other relevant stakeholders (School Based Management Committee (SBMC), Parent-Teachers Association (PTA), Old Students Association, Non-government agencies, Communities, Ministries, School Board, Individuals and other social institutions). This synergy is necessary because a virile and responsive quality assurance system is a building block for sustainable human capital development and the attainment of specified standards that will satisfy the expectations of the institution's customers/society (Ayeni, 2010; Federal Ministry of Education, 2009). These challenges prompted the Ondo State Government to blaze the trail in the establishment of an autonomous Quality Education Assurance Agency to carryout effective monitoring and evaluation of teaching-learning process and bring about consistent improvement in learning achievement and standards in the institutions below the tertiary level.

In addition, several intervention programs (capacity building of teachers, provision of textbooks, science equipment, construction and renovation of classrooms and provision of running grants to school management) are being implemented by the Ondo State Government to revamp the primary education sub-sector for better performance. While at the national level, the Federal Ministry of Education has been implementing significant and goal-oriented programs to improve access and equity, standards and quality assurance, teacher capacity development, funding, technical and vocational education and training, and strengthening the institutional management of education for quality service delivery.

\section{Enhancing Primary Education Quality}

In a bid to achieve high-quality human capital development at the primary school level, the following considerations are essential: All classrooms need to be full of a rich variety of learning materials and opportunities. The classrooms are examples of what is "good" for the children. Access to good sanitation and first aid facilities including water, toilets, and clean, safe, well lighted and comfortable learning environment that meets and, ideally, exceeds the minimum required standards must be provided for the establishment and operations of primary schools.

Crowded classrooms hinder teachers' curriculum delivery, classroom management and pupils' participation and academic achievements. An appropriate teacher/pupil ratio must be maintained to enable pupils have better chance of positive interaction with the teachers; smaller class sizes and/or greater adult-child ratios reflect the program's commitment to human capital development. Manageable class sizes allow the teachers to model appropriate activities, set reasonable expectations for learners' performance and even model discipline; encouraging responsive interpersonal relationships, create positive attitudes toward stimulating learning in young children, and commitment to children's mental, physical and emotional skills development.

Curriculum design and teaching methodology must be child-centered and language-rich with many 
Functional primary education for sustainable quality assurance in human capital development in Nigeria

opportunities for interactive experiences to facilitate mental, social and emotional development. This will also enhance child-initiated learning, and the development of reasoning and problem solving skills. The teachers should be well qualified, trained in child development and be constantly up-to-date on development in pedagogy, classroom management and subject knowledge to maximize outcome for learners.

The welfare of the children is very important and must be given the desired attention; child development refers not only to what is happening within the child but also the necessary care that child requires to survive like good nutrition, clothing, sanitation, education, healthy and safe environment, protection etc. All these are needed to stimulate children for positive learning, nurturing and cultivating their social, emotional, physical and cognitive growth. The Child development and education is influenced by family background (parents, siblings, marital status and children), socioeconomic status (education, employment, status and income), health behavior, personality, feelings and attitudes.

Communities can promote childhood education by providing abundance of books in public libraries; easy access to books in the community at large; and a policy of investing in school libraries, of having a good reading corner in the classroom, and a large number of pupils' textbooks in the communities can stimulate more children to frequently borrow books from the library and engage in silent reading, while the teachers can regularly read aloud to the learners to foster understanding.

Human capital development in the primary school also requires adequate funding to provide appropriate instructional materials, equipment, recreational facilities; and support staff training and motivation to increase the capacity of teachers, headteachers and other relevant stakeholders in adopting a developmentally-appropriate curriculum, providing child-friendly classrooms and meeting the minimum teacher requirements to promote effective teaching and learning processes. Effective primary school programme also requires regular home visits, periodic meetings of stakeholders to review progress being made in order to further improve the school programmes to meet the developmental challenges of chidlren.

Provision of modern learning materials and equipment will promote teaching-learning process. The reading skills can be inculcated with the mastering of alphabet, recognizing letter sounds, rhyming, developing a vocabulary to enhance print knowledge and reading culture etc. Children do not just grow in size; they also develop in mastering what they see in their environment. Children in primary school can learn best when they have objects they can manipulate; it is therefore imperative to introduce concrete instructional materials/real life objects when teaching the pupils. Use of language of the immediate environment as medium of instruction is also important to explain difficult concepts at this formative stage.

\section{Conclusion}

The task of building sustainable quality human capital cannot be over-emphasized; the much desired self-reliance of the citizenry and socio-economic transformation in Nigeria will be an illusion if desirable attention is not accorded to primary education which is the bedrock of human capital development that affects all the sectors of the economy. It is therefore important for the parents, communities, government and other stakeholders in the society to be more engaged in meaningful and goal-oriented partnership to address the challenges facing primary education. This will no doubt expand, improve and sustain the quality of education provision for effective training and development of individual's knowledge and skills for self-reliance and advancement in the nation's economy.

\subsection{Recommendations}

Based on the concept, trends and challenges of primary education, the following recommendations are made for effective implementation to ensure high-quality education provision and capacity development for every child: 
$>$ The school head teachers should provide constant and adequate feedback to the teachers on their instructional task performance to ensure periodic review and facilitate capacity development of teachers through intensive and regular in-house seminar/workshop to improve knowledge, pedagogical skills and competence of teachers in curriculum delivery.

> The school authority should provide constant and comprehensive feedback on learners' academic performance to parents in order to sensitize and encourage them to provide the required textbooks and other learning materials for their children/wards in order to enhance their performance.

> School head teachers should promote learning support to the learners through class exercises, homework, remedial work and healthy academic competitions such as intra and inter-class/school debate, quiz and essays to improve pupils' knowledge, skills, competence and overall performance.

$>$ Government should engage the services of guidance counsellors to provide counselling and other necessary support for the learners to enable them cope with psychological, social and educational challenges, identify their potentials and have better chances in the choice of future careers.

> Government, parents, communities and other commitment-holders in education sector should proactively collaborate with development partners, such as UNICEF and other donor agencies to provide the envisaged quality Child Friendly Schools and other learning materials for effective implementation of primary education curricula and programmes for sustainable human capital development in Nigeria.

$>$ The Federal Government should review upward the $2 \%$ consolidated revenue fund allocated to basic education in order to meet the increasing public demand for sustainable improvement in the quality of physical infrastructure; institutional management; learning resources; teachers' capacity development; curriculum delivery; and learning achievement in primary schools.

D Government should organize periodic capacity development workshops for educational managers (Headteachers and Quality Education Assurance Evaluators) on institutional management and instructional supervision to improve the quality of teaching and learning outcomes in schools.

Government in collaboration with other stakeholders at all levels should organize annual education summit for comprehensive review and assessment of the degree of success in the implementation of primary education curriculum and programs, and producing the desired outputs to ensure sustainable human capital development. 


\section{References:}

Ayeni. A. J. (2010). Teachers' instructional task performance and principals' supervisory roles as correlates of quality assurance in secondary schools in Ondo State. Unpublished Doctoral dissertation, Obafemi Awolowo University, Ile-Ife, Nigeria.

Banjo, A. (1987). Improving English language skills in the educational system. Journal of the Federal Ministry of Education Today, 1(1), 47-55.

Candce Bennett and Associates. (2009). Early childhood education perception poll. Canada: Pearson Foundation. $<$ http://www.pearsonfoundation.org $>$

Cunha, F., \& Heckman, J. J. (2007). The technology of skill formation. The American Economic Review, 97(2), 31-47. <http://dx.doi.org/10.1257/aer.97.2.31>

Federal Ministry of Education. (2009). The state of education in Nigeria. Abuja: Federal Inspectorate Services. Federal Ministry of Education. (2007). Nigeria Education sector diagnosis. Abuja: Nigeria Education Sector Analysis Unit.

Federal Republic of Nigeria. (2004). National policy on education (pp. 11-12). Lagos: NERDC Press.

Federal Ministry of Education. (2003). Education sector status report. Abuja: Federal Ministry of Education with support from UNESCO/Japan Trust Fund Project.

Gregg, P., \& Machin, S. (2000). Child development and success or failure in the Youth Labour Market. NBER Comparative Labour Market Series (pp. 247-288). Chicago: University of Chicago Press.

Heckhausen, J,. \& Heckhausen, H. (2006). Motivation and development [In German]. In J. Heckhausen \& H. Heckhausen, Motivation und Handeln (pp. 283-329). Berlin: Springer Verlag.

Levin, D. (1985). Improving student achievement through mastery learning programs. San Francisco: Jossey-Bass.

Maduekwe, A. N., \& Ajibola, B. C. (2007). Strategies for teaching English grammar: An analysis of grammar lessons in Lagos State schools. Journal of studies in education, 10, 87-101.

Mills, H. R. (1991). Teaching and training. A handbook for instructors. London: Macmillan Publishers.

Okebukola, P. (1996). Meeting the challenges of secondary school administration in Nigeria. Journal of ANCOPSS, 2002, 159-171.

Okebukola, P. (2011). Letter to the president: Phase out poor quality public schools. The Punch, p.40. August, 12.

Simikins, T. (1981). Economics and the management of resources in education. Sheffield, UK: Department of Educational management.

Tsang, M. C. (1988). Cost analysis for educational policy making: A review of cost studies in education in developing countries. Review of Educational Research, 58(2), 181-230. 
Ayeni, A. J. \& Adepoju, T. L. 